\title{
Investigations into the Structure-Function Relationship of the Naturally-Derived Surfactant Glycyrrhizin: Emulsion Stability
}

\author{
Theo Ralla ${ }^{1} \cdot$ Hanna Salminen ${ }^{1} \cdot$ Katharina Braun ${ }^{1} \cdot$ Matthias Edelmann $^{2} \cdot$ Corinna Dawid $^{2} \cdot$ Thomas Hofmann $^{2}$. \\ Jochen Weiss ${ }^{1}$
}

Received: 5 August 2019 / Accepted: 10 January 2020 / Published online: 18 January 2020

(C) The Author(s) 2020

\begin{abstract}
This study describes the emulsion stabilizing properties of the licorice root (Glycyrrhiza glabra L.) derived saponin glycyrrhizin and its corresponding aglycone $18 \beta$-glycyrrhetinic acid to further increase the understanding between structure and functional behavior. For this, we prepared $10 \%$ oil-in-water emulsions and investigated the emulsion stabilizing properties regarding environmental stresses including extreme $\mathrm{pH}$, ionic strength, and temperature. Glycyrrhizin and its aglycone formed nanosized emulsion droplets at neutral $\mathrm{pH}$ that were stable across a broad range of $\mathrm{pH}$-values (pH 5-9), ionic strength (0-200 mM $\mathrm{NaCl}$ ), and temperature (up to $60^{\circ} \mathrm{C}$ ). In contrast, emulsions were unstable at low $\mathrm{pH}(\mathrm{pH}<5$ ), as well as high ionic strength $\left(>200 \mathrm{mM} \mathrm{NaCl},>5 \mathrm{mM} \mathrm{CaCl}_{2}\right.$ ) and temperature as well as after a freeze-thaw cycle. Thereby, the observed instability was mainly attributed to the reduction of electrostatic forces caused by the protonation of free carboxylic acid groups at low $\mathrm{pH}$, screening of electrostatic forces at high ionic strengths, and thin interfaces causing coalescence during a freeze-thaw cycle. Overall, both molecules yielded remarkably stable emulsions at very low molecule-to-oil ratios, and therefore our results are relevant for 'all-natural' emulsion-based foods and beverages, as well as pharmaceutical and cosmetic products.
\end{abstract}

Keywords Emulsion $\cdot$ Saponin $\cdot$ Glycyrrhizin $\cdot 18 \beta$-glycyrrhetinic acid $\cdot$ Interfacial activity

\section{Introduction}

One of the major trends within the food and beverage industry is the replacement of synthetically-derived food additives such as surfactants by 'natural' alternatives. Surfactants are surfaceactive molecules that adsorb to interfaces of immiscible phases, e.g. water and oil, and stabilize these by reducing interfacial tension and thereby facilitating droplet breakup leading to increased kinetic stability of those thermodynamically unstable systems. So far, typically applied natural emulsifiers include plant-derived proteins and phospholipids $[1,2]$. Recently, the group of amphiphilic saponins has attracted the

Jochen Weiss

j.weiss@uni-hohenheim.de

1 Department of Food Physics and Meat Science, University of Hohenheim, Garbenstrasse 25, 70599 Stuttgart, Germany

2 Chair of Food Chemistry and Molecular Sensory Science, Technical University of Munich, Lise-Meitner-Strasse 34,

85354 Freising, Germany interest of academia and industry because of their remarkable surface activity and emulsifying properties [3-8].

Saponins are glycosides composed of one or several hydrophilic sugar chains attached via glycosidic bonds to a hydrophobic backbone, which is of triterpene, steroid alkaloid or steroid nature. These amphiphilic secondary plant metabolites exhibit various functions within plants such as anti-feeding, antifungal, and antibacterial activities and are thought to also exhibit other biological and pharmaceutical properties such as hemolytic, molluscicidal, and anti-inflammatory activities [9]. The licorice (Glycyrrhiza glabra L.) derived saponin is composed of the hydrophobic aglycone $18 \beta$-glycyrrhetinic acid (Fig. 1a) attached to a di-glucuronic acid sugar chain via an ether bond, and is referred to as glycyrrhizin (glycyrrhizic acid, Fig. 1b). This amphiphilic saponin is also the characteristic ingredient of licorice and is used as food additive E958 mainly because of the 30-50 times higher sweetness compared to sucrose [5].

In our previous study [11], we showed that glycyrrhizin and its corresponding aglycone $18 \beta$-glycyrrhetinic acid were not very surface-active. Nevertheless, we observed a slightly higher surface affinity for the glycyrrhizin at an air-water 


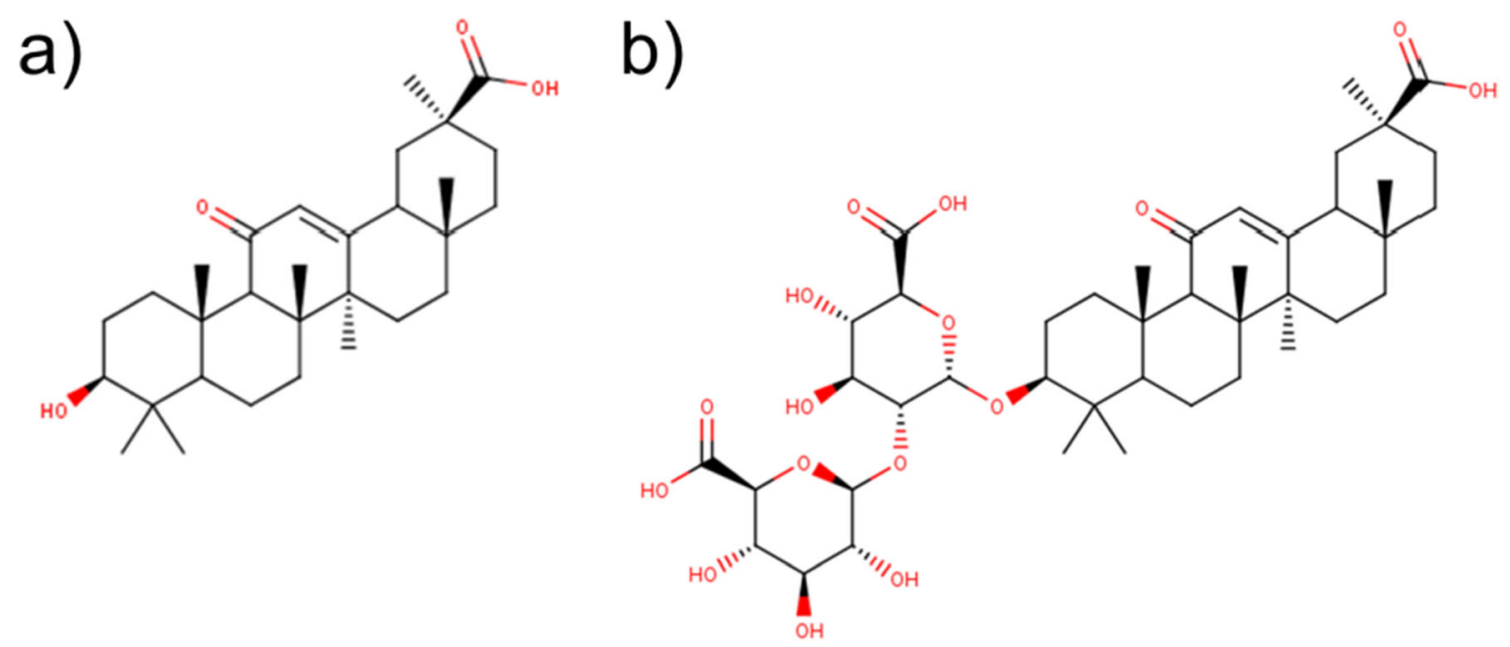

Fig. 1 Structural representation of aglycone 18ß-glycyrrhetinic acid (a) and saponin glycyrrhizin (b). Adapted from Schmid, Dawid, Peters and Hofmann [10]

interface compared to its aglycone, which was attributed to a higher overall polarity of the glycyrrhizin molecule over the aglycone. At an oil-water interface, on the other hand, glycyrrhizin was shown to moderately reduce the interfacial tension, whereas $18 \beta$-glycyrrhetinic acid showed no surface activity at all [11]. The low surface activity has been ascribed to the rather rigid structure of the glycyrrhizin molecule [12]. Moreover, the domination of hydrophobic surfaces over the polar surfaces in both glycyrrhizin and $18 \beta$-glycyrrhetinic acid molecules indicate that the hydrophobic interactions contribute to the forces stabilizing such interfaces [11].

Despite the amphiphilic character of glycyrrhizin, almost no reports about the emulsion stabilizing properties have been published so far except for our recent study [11]. There we showed that both glycyrrhizin and its aglycone were able to form nanosized emulsions regardless of their low interfacial activity as described above. The generally established requirements for emulsifying properties of surfactants and emulsifiers include two key roles: (i) emulsion formation, which again requires rapid adsorption and high interfacial tension reduction leading to facilitation of droplet breakup during homogenization, but also (ii) emulsion stabilization, which again requires the generation of both a strong repulsive force as well as a resistant layer to prevent droplet aggregation [13]. However, an efficient emulsion formation does not always correlate with the interfacial activity [11].

Keeping thermodynamically unstable emulsions kinetically stable throughout the expected shelf life of the product is essential as they can become unstable through numerous instability mechanisms including coalescence, flocculation, as well as gravitational separation, and Ostwald ripening. These processes highly depend on extrinsic factors, especially $\mathrm{pH}$, ionic strength, and temperature, which may differ for each emulsion-based application [1, 13, 14]. Therefore, in this study, we systematically investigated for the first time the impact of solvent conditions ( $\mathrm{pH}$, ionic strength) and processing conditions (heating, freeze-thawing) on $10 \%$ oilin-water emulsions ( $\mathrm{pH} \mathrm{7)}$ stabilized by the saponin glycyrrhizin and its aglycone $18 \beta$-glycyrrhetinic acid. These factors are highly relevant in understanding the molecular stabilization processes and further applications in the food or related industries.

\section{Materials and Methods}

\section{Materials}

Glycyrrhizin ammoniacal $\left(\mathrm{C}_{42} \mathrm{H}_{65} \mathrm{NO}_{16}, 839.98 \mathrm{~g} \mathrm{~mol}^{-1}\right.$, $\geq 98 \%$ ) was obtained from ExtraSynthese SAS (Genay Cedex, France). The corresponding aglycone $18 \beta$ glycyrrhetinic acid $\left(\mathrm{C}_{30} \mathrm{H}_{46} \mathrm{O}_{4}, 470.68 \mathrm{~g} \mathrm{~mol}^{-1}, \geq 98 \%\right)$ was purchased from Sigma-Aldrich Co. (Steinheim, Germany). The medium chain triglyceride oil (Miglyol $812 \mathrm{~N}$ ) was obtained from Cremer Oleo GmbH \& Co. KG (Hamburg, Germany). Sodium phosphate monobasic monohydrate ( $\geq 99.0 \%)$, sodium phosphate dibasic heptahydrate ( $\geq 99.0 \%)$, hydrochloric acid $(\geq 37.0 \%)$, sodium hydroxide $(\geq 98.0 \%)$, citric acid monohydrate $(\geq 99.5 \%)$, and sodium azide $(\geq 99.0 \%$ ) were purchased from Carl Roth $\mathrm{GmbH} \& \mathrm{Co}$. KG (Karlsruhe, Germany). Deionized water was used for all subsequent experiments.

\section{Purification and quantification of the used glycyrrhizin and 18ß-glycyrrhizinic acid}

Glycyrrhizin is typically bound to ammonia (glycyrrhizin ammoniacal) to increase solubility. To ensure no effect from ammonia, we purified the substance by solubilizing $50 \mathrm{~g}$ of glycyrrhizin ammoniacal in $3 \mathrm{~L}$ of purified water and used formic acid $\left(2.2 \cdot 10^{-3} \mathrm{~mol} \mathrm{~L}^{-1}\right.$, corresponds to $\left.1 \%\right)$ to reduce the $\mathrm{pH}$ to 3 . The solution was freeze-dried and the process was 
repeated to make sure that no ammonia was present. A quantitative nuclear magnetic resonance spectroscopy (qNMR) as reported by Frank, Kreissl, Daschner, and Hoffman [15] was applied to determine the purities of glycyrrhizin and $18 \beta$ glycyrrhizinic acid. The molecular weight of the glycyrrhizin after purification was $822.94 \mathrm{~g} \mathrm{~mol}^{-1}$.

\section{Molecular characteristic prediction}

To predict $\mathrm{pK}_{\mathrm{a}}$-values of the used glycyrrhizin and its corresponding aglycone, the software Marvin (Marvin 18.29, 2018, ChemAxon, https://chemaxon.com) and the corresponding protonation bundle was used to draw, display, and characterize the chemical structures.

\section{Solution Preparation for Interfacial Property Characterization}

Aqueous glycyrrhizin and $18 \beta$-glycyrrhetinic acid solutions $\left(5.0 \cdot 10^{-3} \mathrm{~mol} \mathrm{~L}^{-1}\right)$ were prepared by dispersing appropriate amounts in $10 \mathrm{mM}$ sodium phosphate buffer at $\mathrm{pH}$ 7. All solutions were stirred overnight and the $\mathrm{pH}$ was re-adjusted to $\mathrm{pH} 7$ using 0.1 and $1 \mathrm{M} \mathrm{NaOH}$ and/or $\mathrm{HCl}$, if necessary.

\section{Emulsion Preparation}

Coarse emulsions were prepared by blending $90 \%(w / w)$ aqueous glycyrrhizin or its corresponding aglycone $18 \beta$ glycyrrhetinic acid with $10 \%(w / w)$ medium chain triglyceride oil using a high-shear blender (Silent Crusher M, Heidolph Instruments $\mathrm{GmbH} \& \mathrm{Co}$. KG, Schwabach, Germany) at $15,000 \mathrm{rpm}$ for $2 \mathrm{~min}$. Fine emulsions were prepared by passing the coarse emulsion through a high-pressure homogenizer (EmulsiFlex-C3, Avestin, Ottawa, Canada) at 10,000 psi for four times.

\section{Emulsion Stability}

Oil-in-water emulsions (10\% Miglyol oil, $5.0 \cdot 10^{-3} \mathrm{~mol} \mathrm{~L}^{-1}$, $\mathrm{pH} 7$ ) were transferred into $10 \mathrm{~mL}$ glass test tubes, exposed to various stress parameters, and stored at $5{ }^{\circ} \mathrm{C}$ for $24 \mathrm{~h}$ prior to analysis, unless stated otherwise. If necessary, $\mathrm{pH}$ was readjusted using 0.1 or $1 \mathrm{M} \mathrm{HCl}$ and/or $\mathrm{NaOH}$, unless stated otherwise.

Influence of $\mathrm{pH}$ Emulsion samples were adjusted to the appropriate $\mathrm{pH}$ (pH 2 to 9) using $0.1,1$, or $2 \mathrm{M} \mathrm{HCl}, \mathrm{NaOH}$, and $\mathrm{pH}$ adjusted buffer to obtain a final oil droplet concentration of $5 \%(w / \mathrm{w})$.
Influence of lonic Strength Emulsion samples were adjusted to the specified ionic strength $(0$ to $0.5 \mathrm{M} \mathrm{NaCl}, 0$ to $0.1 \mathrm{M}$ $\mathrm{CaCl}_{2}$ ) using ionic strength and $\mathrm{pH}$-adjusted buffer to obtain a final oil droplet concentration of $5 \%(w / w)$.

Influence of Temperature Emulsion samples were incubated at 50,75 or $90{ }^{\circ} \mathrm{C}$ for $30 \mathrm{~min}$. To prevent microbial growth, $0.03 \%(w / \mathrm{w})$ sodium azide was added.

Influence of Freeze-Thaw-Cycle Emulsion samples were frozen for 12 to $14 \mathrm{~h}$ at $-28{ }^{\circ} \mathrm{C}$ and thawed for $3 \mathrm{~h}$ at $25^{\circ} \mathrm{C}$.

\section{Particle characterization}

Particle sizing was performed using a static light scattering device (Horiba LA-950, Retsch Technology GmbH, Haan, Germany). For this, emulsions were diluted in $\mathrm{pH}$ and ionic strength adjusted buffer to prevent multiple-scattering effects. The refractive indices were set to 1.33 and 1.47 for the continuous and the dispersed phase, respectively. Mean particle sizes are displayed as surface-based $\left(\mathrm{d}_{32}\right.$, Eq. 1$)$ and volumebased diameters $\left(\mathrm{d}_{43}\right.$, Eq. 2),

$d_{32}=\frac{\sum d_{i} n_{i}^{3}}{d \sum d_{i} n_{i}^{2}}$

$d_{43}=\frac{\sum d_{i} n_{i}^{4}}{d \sum d_{i} n_{i}^{3}}$

where $n_{i}$ is the number of droplets of diameter $d_{i}$. The $d_{32}$ focuses on smaller droplets, whereas the $d_{43}$ takes larger droplets also into account. For $\zeta$-potential determination, emulsions were diluted 1:50 using $\mathrm{pH}$ and ionic strength adjusted buffer to prevent multiple-scattering effects and then measured in a particle electrophoreses instrument (Zetasizer Nano ZS, Malvern Instruments, Malvern, UK).

\section{Optical Microscopy}

All emulsions were visually observed using an optical light microscope (AxioScope A1, Carl Zeiss Microimaging GmbH, Goettingen, Germany) equipped with a digital camera and 20x and 40x objectives, and scale bars were added afterwards using the software ImageJ [16].

\section{Statistical Analysis}

All performed measurements were at least duplicated on at least two independently prepared samples. All reported values represent means and standard deviations. 


\section{Results and Discussion}

Keeping thermodynamically unstable systems kinetically stable over the shelf life is crucial as unstable products are often rejected by consumers. Emulsion stability is influenced by various internal parameters including surfactant characteristics and content, but also in particular by external parameters such as $\mathrm{pH}$, ionic strength, and temperature. Consequently, we determined the influence of external parameters on the stability of $10 \%(w / w)$ oil-in-water emulsions stabilized by glycyrrhizin and its aglycone at a concentration of $5.0 \cdot 10^{-3} \mathrm{~mol} \mathrm{~L}^{-1}(\mathrm{pH} 7)$ prepared by highpressure homogenization at 10,000 psi. The surfactant concentration used was selected based on our previous results [11] investigating the interfacial and emulsion forming properties, which showed that higher concentrations than the used one did not lead to a further reduction of mean particle size but stayed at a plateau. The emulsion stabilization was attributed to the hydrophobic interactions between the surfactant molecules originating from the high van der Waals surfaces but also to the high net negative charges contributing to the electrostatic repulsion between the emulsion droplets [11]. We also concluded from the theoretical surface loads ( $\Gamma_{\text {glycyrrhizin }} \sim 1.2 \mathrm{mg} \mathrm{m}^{-2}$; $\Gamma_{\text {glycyrrhetinic acid }} \sim 0.8 \mathrm{mg} \mathrm{m}^{-2}$ ) that both molecules may occupy an interfacial configuration known as lay-on configuration in which the hydrophobic backbone lays flat in the oil phase and the hydrophilic glycone (in glycyrrhizin only) protrudes into the water phase. This was unexpected as monodesmosidic saponins typically cover an interfacial area of $\sim 0.4-0.5 \mathrm{mg} \mathrm{m}^{-2}$ which corresponds to a configuration known as end-on configuration [17]. The low surface load was attributed to the strongly negatively charged carboxylic acid groups within both molecules that led to a high repulsive charge and consequently to the prevention of further adsorption of additional molecules at the interface [11].

\section{Influence of $\mathrm{pH}$}

Emulsions stabilized by glycyrrhizin and $18 \beta$-glycyrrhetinic acid were stable across a broad pH-range (Fig. 2): For the glycyrrhizin stabilized emulsion, the surface- and volumebased mean particle sizes stayed fairly constant between $\mathrm{pH} 4$ to $9\left(\mathrm{~d}_{32}=0.192 \pm 0.016 \mu \mathrm{m} ; \mathrm{d}_{43}=0.277 \pm 0.059 \mu \mathrm{m}\right.$, Fig. 2a) and increased to $>1 \mu \mathrm{m}$ when lowering the $\mathrm{pH}$ to 3 and 2. Furthermore, the particle size distributions plotted as surface- and volume-based distribution were monomodal at all tested $\mathrm{pH}$-values, although the narrow peaks shifted from $\sim 0.2 \mu \mathrm{m}$ between $\mathrm{pH} 4$ to 9 to broader peaks with larger particle size values at lower $\mathrm{pH}$-values (data not shown). It should be noted that the used Mie theory assumes spherical particles for particle size measurements with a well-defined refractive index but any associated or flocculated particles may have become dissociated during the particle sizing leading to incorrect results as observed in the microscopic images. Nevertheless, all particle sizes measurements corresponded well with microscopic observations showing highly aggregated emulsions at $\mathrm{pH} \leq 3$ (Figs. 2, 3). In contrast, the aglycone (18 $\beta$-glycyrrhetinic acid) stabilized emulsions were stable between pH 6 to $9\left(\mathrm{~d}_{32}=0.268 \pm 0.076 \mu \mathrm{m} ; \mathrm{d}_{43}=0.442 \pm\right.$ $0.129 \mu \mathrm{m}$, Fig. 2) with monomodal particle size distributions (data not shown). At pH 2 to 5, these emulsions exhibited large, micron-sized mean diameters with broad particle size distributions (data not shown). Furthermore, the strong flocculation observed (Fig. 2b) interfered in attaining reproducible particle size data at $\mathrm{pH} 2$ and 3, leading to irreproducible data.

The stability of the emulsions at higher $\mathrm{pH}$-values can be explained by the $\zeta$-potential measurements: Glycyrrhizin stabilized emulsions had a high negative charge of around $60 \mathrm{mV}$ between $\mathrm{pH}$ 4-9 (Fig. 2a), and this high electrostatic repulsion between the individual oil droplets contributed to the stability of the emulsions. Upon lowering the $\mathrm{pH}$ to 3 , the charge of the emulsion droplets increased to around $-52 \mathrm{mV}$,
Fig. 2 Influence of storage $\mathrm{pH}$ on (a) mean particle size $\left(\mathrm{d}_{43}\right)$ and $\zeta$ potential, as well as (b) visual appearance of $10 \%(w / w)$ oil-inwater emulsions stabilized by $5.0 \cdot 10^{-3} \mathrm{~mol} \mathrm{~L}^{-1}$ glycyrrhizin and its corresponding aglycone $18 \beta$ glycyrrhetinic acid produced under standardized high-pressure homogenization conditions ( $\mathrm{pH} 7,10,000 \mathrm{psi}, 4$ cycles) after $24 \mathrm{~h}$ storage. Irreproducible data not shown for $\mathrm{pH} 2$ and 3 for glycyrrhetinic acid stabilized emulsions due to phase separation a)

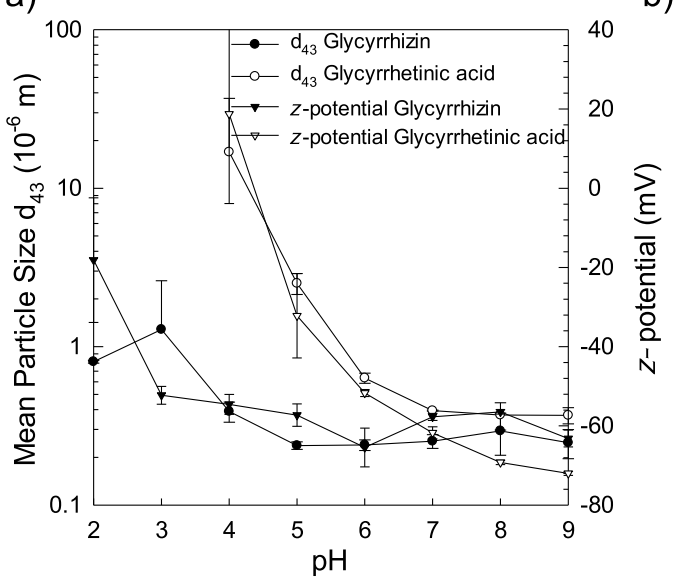

b)
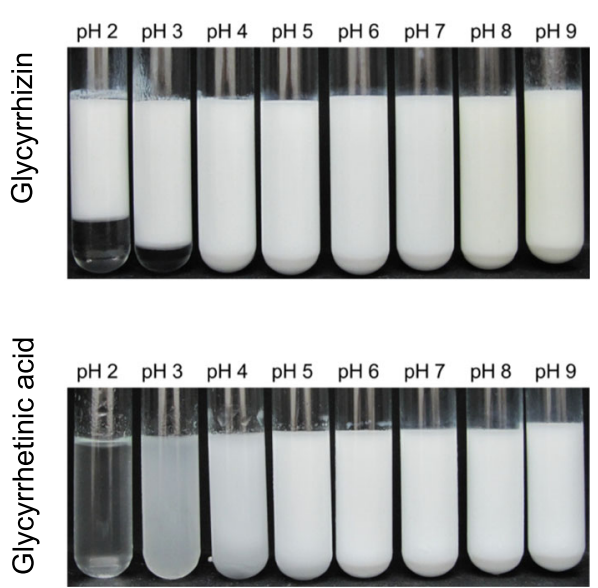
Fig. 3 Influence of storage $\mathrm{pH}$ ( $\mathrm{pH} 2$ to 9 ), ionic strength (0 to $500 \mathrm{mM} \mathrm{NaCl}, 0$ to $100 \mathrm{mM}$ $\left.\mathrm{CaCl}_{2}\right)$, as well as temperature (5 to $90{ }^{\circ} \mathrm{C}$ ) on the microstructure of $10 \%(w / w)$ oil-in-water emulsions stabilized by $5.0 \cdot 10^{-3} \mathrm{~mol} \mathrm{~L}^{-1}$ glycyrrhizin and its corresponding aglycone $18 \beta$-glycyrrhetinic acid produced under standardized high-pressure homogenization conditions ( $\mathrm{pH} \mathrm{7,10,000} \mathrm{psi,}$ 4 cycles) after $24 \mathrm{~h}$ storage
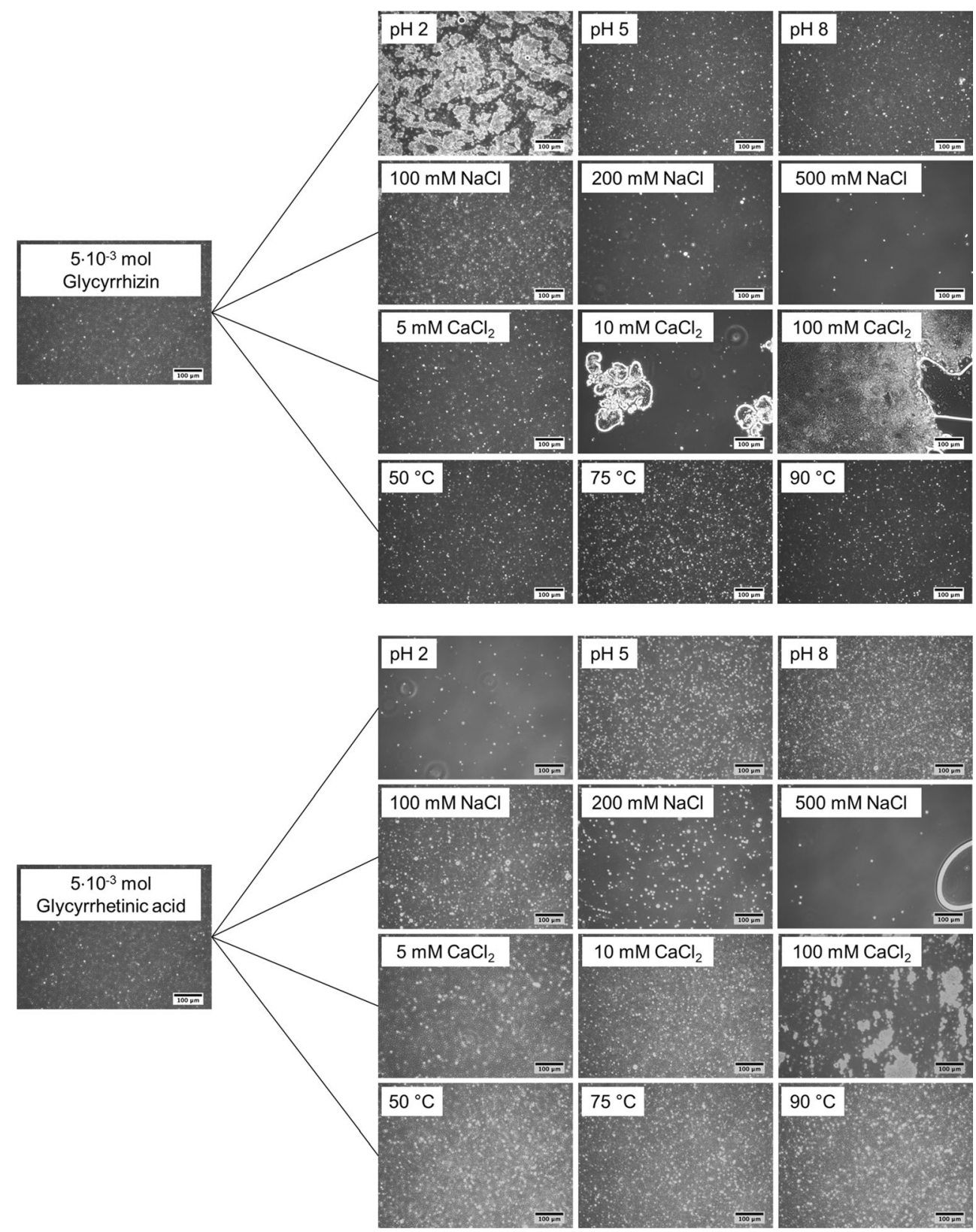

which should have provided sufficient electrostatic repulsion to prevent flocculation. However, as this was not the case, other molecular interactions may have taken place. As macroscopic images revealed that creaming occurred at $\mathrm{pH} 2$ and 3 (Fig. 2b), and microscopic images showed aggregated emulsion samples (Fig. 3), it is likely that the attractive van der Waals forces were able to act between the partially uncovered oil droplets and/or due to the close proximity of the droplets in the flocculated stage. Consequently, the aggregation interfered with the electrophoretic light scattering measurements, thus leading to changes in the obtained $\zeta$-potential values. Therefore, $\zeta$-potential values in aggregated emulsion samples should be treated with caution. At $\mathrm{pH} 2$, the $\zeta$ potential increased further to $-18.1 \pm 15.4 \mathrm{mV}$ (Fig. 2a), and the magnitude of the electrostatic repulsion weakened dramatically, thus leading to flocculation (Figs. 2b, and 3). Similarly, the $\zeta$-potential of $18 \beta$-glycyrrhetinic acid stabilized emulsions stayed fairly constant between $\mathrm{pH} 7$ to 9 with a high negative charge between -60 and $-70 \mathrm{mV}$ but continued to increase towards electro-neutrality upon lowering the pH (Fig. 2a).

The origin of the negative charge may be attributed to the presence of a free carboxylic acid group within the hydrophobic aglycone attached at position C-30, and two additional ones within the glucuronic acid moieties for the saponin (Fig. 1). A typical $\mathrm{pK}_{\mathrm{a}}$ value for this functional group is around $\mathrm{pH} 3.8$ as reported for Quillaja saponin extract [18], which also corresponds with the predicted and literature reported values of $\mathrm{pK}_{\mathrm{a}}$ 
for glycyrrhizin (4.4) and its corresponding aglycone $18 \beta$ glycyrrhetinic acid (3.0) [19]: At high $\mathrm{pH}\left(\mathrm{pH}>>\mathrm{pK}_{\mathrm{a}}\right)$, most of the carboxylic acid groups are dissociated and therefore highly negatively charged (- $\mathrm{COO}^{-}$), providing the high negative charge at neutral $\mathrm{pH}$. However, at lower $\mathrm{pH}$ values $\left(\mathrm{pH}<<\mathrm{pK}_{\mathrm{a}}\right)$, most of these functional groups become protonated $(-\mathrm{COOH})$ and therefore the charge of the molecules decreases and the charge of the molecules becomes almost electro-neutral as observed at very acidic conditions at $\mathrm{pH} 2$ (Fig. 2).

Overall, our results indicated that the saponin glycyrrhizin showed a better stabilization against $\mathrm{pH}$ changes compared to the aglycone. The performance of glycyrrhizin and its aglycone is comparable to emulsions stabilized with crude saponin extracts derived from sugar beet, red beet and oat bran as well as to purified saponin extracts derived from Quillaja, Korean ginseng and Yucca, for which the observed instability at very acidic conditions was mainly attributed to the previously mentioned reduced repulsive forces [7, 8, 20-24].

\section{Influence of lonic Strength}

In this series of tests, the emulsions were subjected to changes in the solvent ionic strength $\left(\mathrm{NaCl} 0\right.$ to $500 \mathrm{mM}, \mathrm{CaCl}_{2} 0$ to $100 \mathrm{mM}$ ).

$\mathrm{NaCl}$. Emulsions stabilized by glycyrrhizin showed a slight increase in mean particle size at $\leq 200 \mathrm{mM} \mathrm{NaCl}\left(\mathrm{d}_{32}=0.191\right.$ $\left.\pm 0.017 \mu \mathrm{m} ; \mathrm{d}_{43}=4.674 \pm 7.323 \mu \mathrm{m}\right)$, however, no flocculation was observed macroscopically (Fig. 3b) or microscopically (data not shown). At $\geq 300 \mathrm{mM} \mathrm{NaCl}$, the emulsions began to flocculate as visible in macroscopic (Fig. 4b) and microscopy imaging (Fig. 3). A further increase of ionic strength to $500 \mathrm{mM} \mathrm{NaCl}$ led to phase separation of the emulsions (Fig. 4b). In contrast, emulsions stabilized by $18 \beta$-glycyrrhetinic acid were more prone to changes in ionic strength: Already low ionic strengths $(\geq 200 \mathrm{mM}$ ) induced coalescence, and at $\geq 300 \mathrm{mM} \mathrm{NaCl}$ the emulsions were completely phase separated (Fig. 4b). The strong increase in mean particle size can be explained by their $\zeta$-potential: Glycyrrhizin stabilized emulsions had a strong negative charge of $-45 \mathrm{mV}$ at $\leq 200 \mathrm{mM} \mathrm{NaCl}$, whereas this charge dramatically increased to $-28 \mathrm{mV}$ at $500 \mathrm{mM} \mathrm{NaCl}$ (Fig. $4 a)$. Similarly, the $\zeta$-potential for $18 \beta$-glycyrrhetinic acid stabilized emulsions increased from around $-60 \mathrm{mV}$ to $-24 \mathrm{mV}$ at $200 \mathrm{mM} \mathrm{NaCl}$, whereas a further increase of ionic strength led to complete phase separation of which no $\zeta$-potential could be measured (Fig. 4a). The observed increase of $\zeta$ potential towards electro-neutrality with increasing ionic strength corresponds well with the increase in mean particle size (Fig. 4a), also observable in microscopic images (Fig. 3), which may be attributed to insufficient long-range electrostatic repulsion forces to prevent the droplets coming in close proximity as the $\mathrm{Na}^{+}$- and $\mathrm{Cl}^{-}$-ions screened these repulsive forces (as shown in Fig. 4a). This enabled the short-range attraction forces such as created by van der Waals interactions [14] to cause droplet association leading to the observed droplet flocculation or coalescence.

$\mathrm{CaCl}_{2}$. Next, we investigated the emulsion stability in the presence of multivalent ions using $\mathrm{CaCl}_{2}$ (Fig. 4). As monovalent ions (e.g., $\mathrm{Na}^{+}, \mathrm{K}^{+}$) only screen electrostatic charges, multivalent ions (e.g., $\mathrm{Ca}^{2+}, \mathrm{Al}^{3+}$ ) may additionally bind to the surface of droplets causing charge reversal, i.e. initially negatively charged droplets may become positively charged by binding of bivalent ions. At $5 \mathrm{mM} \mathrm{CaCl}_{2}$, the particle sizes of emulsions stabilized by glycyrrhizin $\left(\mathrm{d}_{32}=0.184 \pm\right.$ a)

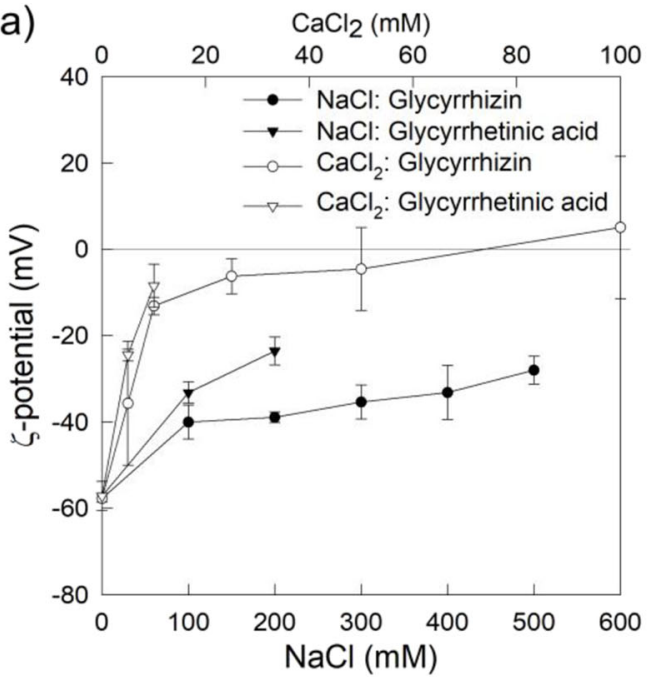

Fig. 4 Influence of ionic strength $\left(\mathrm{NaCl}, \mathrm{CaCl}_{2}\right)$ on (a) $\zeta$-potential, as well as (b) visual appearance of $10 \%(w / w)$ oil-in-water emulsions stabilized by $5.0 \cdot 10^{-3} \mathrm{~mol} \mathrm{~L}^{-1}$ glycyrrhizin and its corresponding aglycone $18 \beta$-glycyrrhetinic acid produced under standardized high-pressure b)
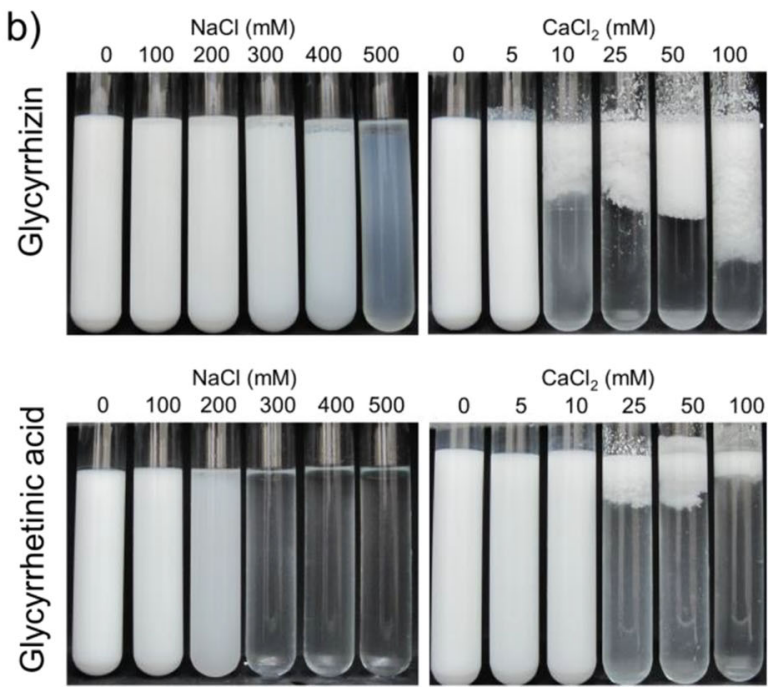

homogenization conditions ( $\mathrm{pH} 7,10,000 \mathrm{psi}, 4$ cycles) after $24 \mathrm{~h}$ storage. Irreproducible data not shown for very high ionic strength due to emulsion phase separation 
$0.001 \mu \mathrm{m})$ and glycyrrhetinic acid $\left(\mathrm{d}_{32}=0.235 \pm 0.022 \mu \mathrm{m}\right)$ remained stable, although the $d_{43}$ - values increased slightly $\left(\mathrm{d}_{43, \text { saponin }}=0.356 \pm 0.011 \mu \mathrm{m} ; \mathrm{d}_{43, \text { aglycone }}=0.418 \pm\right.$ $0.089 \mu \mathrm{m})($ data not shown). A further increase of ionic strength led to large flocs which led to irreproducible particle size measurements as any associated droplets may have become dissociated. Similarly, the $\zeta$-potential for glycyrrhizin stabilized emulsions increased from $-54 \mathrm{mV}$ to $-5 \mathrm{mV}$ at $50 \mathrm{mM} \mathrm{CaCl}_{2}$, and reached even positive values of $5 \mathrm{mV}$ at $100 \mathrm{mM} \mathrm{CaCl}_{2}$ (Fig. 4a). Likewise, the $\zeta$-potential for $18 \beta$ glycyrrhetinic acid stabilized emulsions increased from $-57 \mathrm{mV}$ to $-9 \mathrm{mV}$ at $10 \mathrm{mM} \mathrm{CaCl}_{2}$ (Fig. $4 \mathrm{a}$ ), whereas a further increase of ionic strength led to phase separation (Fig. 4b). The increase of both the mean particle size and $\zeta$-potential (Fig. 4a) correspond well with the macro- and microscopic images showing fine dispersed emulsion droplets at rather low ionic strength, whereas a further increase of ionic strength showed flocculated emulsions, or even complete phase separation (Fig. 4b, 3). The relatively low stability of glycyrrhizin stabilized emulsions towards mono- and divalent ions may be caused by the high amount of negative charge carriers (carboxylic acid groups) being present in the saponin molecule especially because of the two glucuronic acid molecules, attracting positive ions and thereby bringing the electrical charge towards electro-neutrality much faster. Similar instability at such high ionic strength was also observed for emulsions stabilized by a variety of saponin extracts including Quillaja, Korean ginseng, Yucca, and oat bran [7, 20-23]. The authors attributed the observed instability to the screening of repulsive charges by mobile charge carriers $\left(\mathrm{NaCl}, \mathrm{CaCl}_{2}\right)$. The long-range attractive interactions including van der Waals become stronger and start to dominate the long-range repulsive interactions including the determined electrostatic interactions causing droplet association [7]. Overall, emulsions stabilized by glycyrrhizin and its corresponding aglycone were stable at very low ionic strengths, whereas higher concentrations led to the screening of electrical charges, causing flocculation or even phase separation.

\section{Influence of Thermal Processing}

Emulsions stabilized using glycyrrhizin or $18 \beta$-glycyrrhetinic acid were fairly stable when stored at $5^{\circ} \mathrm{C}$ for $24 \mathrm{~h}$, but increased slightly in size when heated for $30 \mathrm{~min}$ to 50,75 , and $90{ }^{\circ} \mathrm{C}$ (Table 1). While the surface-based mean particle size of the saponin stabilized emulsions stayed fairly constant $\left(d_{32}=0.184 \pm\right.$ $0.005 \mu \mathrm{m})$, the volume-based sizes $\left(\mathrm{d}_{43}\right)$ increased from $0.253 \pm$ $0.025 \mu \mathrm{m}$ at $5{ }^{\circ} \mathrm{C}$ to $>1 \mu \mathrm{m}$ at temperatures of $\leq 50{ }^{\circ} \mathrm{C}$. This data corresponds well with microscopic images showing larger emulsion droplets (Fig. 3). Furthermore, oiling-off was observed, indicating emulsions were highly susceptible towards coalescence at increased temperature. Similarly, the aglycone stabilized emulsions showed an increase in mean particle size when heated $\leq 50{ }^{\circ} \mathrm{C}$ : The $\mathrm{d}_{43}$-values increased from $0.184 \pm 0.005 \mu \mathrm{m}$ at $5{ }^{\circ} \mathrm{C}$ to $0.341 \pm 0.052 \mu \mathrm{m}$ at $90{ }^{\circ} \mathrm{C}$. These results indicate that glycyrrhizin and glycyrrhetinic acid stabilized emulsions were prone to coalescence when heated, which may be attributed to thermal degradation of saponins as reported by Jood, Chauhan and Kapoor [25], who reported a decrease of saponin content by over $60 \%$ after autoclaving. Thereby, thermal treatment may lead to the cleavage of the glycosidic linkage (ether bond) between the hemiacetal hydroxyl of glucuronic acid and the triterpene backbone liberating the di-saccharide from its hydrophobic sapogenin which is then unable to fully stabilize emulsions at elevated temperatures as observed for the aglycone stabilized emulsions. Similar instability phenomenon was also reported for crude saponin extract stabilized emulsions derived from sugar beet, red beet, oat bran and Korean ginseng as well as purified saponin extracts from Quillaja and Yucca [8, 20-24], and was mainly attributed to cleavage of the glycosidic linkage of the saponins in combination with partial denaturation of remaining byproducts in the extracts such as proteins.

\section{Influence of Long-Term Storage}

The long-term stability of emulsions is crucial for commercial applications regarding their shelf life. Therefore, we determined the stability of $10 \%(w / w)$ oil-in-water emulsions (pH 7) stabilized by glycyrrhizin and its corresponding aglycone at different temperatures $\left(5,25\right.$, and $\left.55^{\circ} \mathrm{C}\right)$. We observed no increase in mean particle size when emulsions were stored at $5{ }^{\circ} \mathrm{C}\left(\mathrm{d}_{43}=0.281 \pm 0.012 \mu \mathrm{m}\right)$ (Table 2). However, all emulsions stored at elevated temperatures of 25 and $55^{\circ} \mathrm{C}$ became unstable, showing phase separation after 14 or 7 days, respectively. In contrast, emulsions stabilized by the aglycone $18 \beta$ glycyrrhetinic acid remained stable over $35 \mathrm{~d}$ when stored at $5{ }^{\circ} \mathrm{C}\left(\mathrm{d}_{43}=0.306 \pm 0.006 \mu \mathrm{m}\right)$ and over $28 \mathrm{~d}$ when stored at $25{ }^{\circ} \mathrm{C}\left(\mathrm{d}_{43}=0.315 \pm 0.054 \mu \mathrm{m}\right)$. These emulsions, however, became also unstable and showed complete phase separation when stored at $55^{\circ} \mathrm{C}$ over the course of 7 days. The increased stability towards destabilization such as the observed phase separation of the aglycone glycyrrhetinic acid stabilized emulsions compared to those stabilized by glycyrrhizin remains still unclear, however, we propose that the emulsifying properties are mainly due to the aglycone rather than the sugar chain attached to it, as reported in our previous study [11].

\section{Influence of Freeze-Thaw Cycle}

The stability after thermal processing such as freezing and thawing is crucial for most commercially-available dispersed food systems regarding their shelf life. Emulsions stabilized by glycyrrhizin or its corresponding aglycone $18 \beta$-glycyrrhetinic acid were unstable after one freeze-thaw cycle and showed phase separation (data not shown). Such behavior was also observed for other emulsions stabilized by saponins derived from sugar 
Table 1 Mean particle size $\left(\mathrm{d}_{32}\right.$ and $\mathrm{d}_{43}$, in $\left.\mu \mathrm{m}\right)$ of oil-in-water emulsions $\left(10 \% \mathrm{w} / \mathrm{w}\right.$ Miglyol oil, $\mathrm{pH} 7$ ) stabilized by $5.0 \times 10^{-3} \mathrm{~mol} \mathrm{~L}^{-1}$ glycyrrhizin or its corresponding aglycone $18 \beta$-glycyrrhetinic acid produced under standardized high-pressure homogenization conditions $\left(10,000 \mathrm{psi}, 4\right.$ cycles) after heat treatment $(30 \mathrm{~min})$ at 50,75 , and $90^{\circ} \mathrm{C}$

\begin{tabular}{|c|c|c|c|c|}
\hline \multirow[t]{2}{*}{ Temperature $\left({ }^{\circ} \mathrm{C}\right)$} & \multicolumn{2}{|l|}{ Glycyrrhizin } & \multicolumn{2}{|c|}{ Glycyrrhetinic acid } \\
\hline & $d_{32}$ & $\mathrm{~d}_{43}$ & $d_{32}$ & $\mathrm{~d}_{43}$ \\
\hline 5 & $0.189 \pm 0.000$ & $0.235 \pm 0.025$ & $0.224 \pm 0.002$ & $0.412 \pm 0.060$ \\
\hline 50 & $0.181 \pm 0.011$ & $0.248 \pm 0.025$ & $0.232 \pm 0.001$ & $0.352 \pm 0.010$ \\
\hline 75 & $0.178 \pm 0.009$ & $0.325 \pm 0.028$ & $0.239 \pm 0.016$ & $0.345 \pm 0.023$ \\
\hline 90 & $0.188 \pm 0.004$ & $0.375 \pm 0.107$ & $0.236 \pm 0.019$ & $0.316 \pm 0.017$ \\
\hline
\end{tabular}

beet, red beet, and oat bran as well as Korean ginseng, Quillaja, and Yucca [8, 20-24]. The underlying mechanism for this behavior is most likely coalescence caused by freeze-concentration of the system as the water starts to crystallize bringing the dispersed liquid oil droplets into unfavorably close proximity [26]. Thus, the thickness of the formed interfaces dominates the stability towards such processing. Thin interfaces accompanied with low surface loads (typically observed for e.g. lecithin) are known to become unstable during freeze-thawing. In our case, the low surface load of $\sim 1.2 \mathrm{mg} \mathrm{m}^{-2}$, which was triggered by the high negative charge at neutral $\mathrm{pH}$ (induced by the highly charged carboxylic acid groups within both molecules) created a thin interface which was most likely insufficient to prevent the observed destabilization. Furthermore, the poor performance may also be attributed to the inability of glycyrrhizin $[11,27,28]$ and its corresponding aglycone [11] to form viscoelastic interfaces which may be beneficial during such harsh treatments. Such inelasticity is unusual for monodesmosidic saponins and may be the result of the relatively short di-glucuronic acid chain which is unable to form intermolecular hydrogen bonds between neighboring sugar molecules or may even be fully absent in the case of the aglycone [11]. On the other hand, Quillaja saponins can form highly viscoelastic interfaces [17, 29] but also cannot stabilize emulsions against freeze-thawing [21]. Therefore, the role of the elasticity at the interface on the freeze-thaw stability is unclear and further studies should be carried out in the future.

\section{Conclusion}

We have carried out a systematic study of the emulsion stabilizing properties of the naturally-derived, food-grade saponin glycyrrhizin and its corresponding aglycone $18 \beta$-glycyrrhetinic acid. Both molecules formed highly charged nano-sized oil-inwater emulsion droplets that were stable to various external stresses. In detail, glycyrrhizin and $18 \beta$-glycyrrhetinic acid stabilized emulsions were stable over a broad $\mathrm{pH}$-range, ionic strength, as well as storage times, and temperatures, however, glycyrrhizin showed a slightly better stability against changes in $\mathrm{pH}$ and $\mathrm{NaCl}$ additions over the aglycone. The overall emulsion stabilization can be mainly attributed to the van der Waals forces between the rather hydrophobic surfactant molecules and strong electrostatic repulsion caused by free carboxylic acid groups in both molecules leading to highly negative $\zeta$-potentials. In contrast, protonation of these carboxylic acid groups at lower $\mathrm{pH}$ leading to the reduction of electrostatic repulsion operating between the droplets led to unstable emulsions at low $\mathrm{pH}(\mathrm{pH}<$ 5), whereas the observed instability at higher ionic strengths was attributed to the screening of electrostatic repulsion by mono- and bivalent ions. Overall, our results show that the naturally-derived saponin glycyrrhizin and its corresponding aglycone $18 \beta$ glycyrrhetinic acid are effective molecules to form and stabilize oil-in-water emulsions that may be suitable for various applications. Although a clear relationship between molecular structure
Table 2 Mean particle size $\left(\mathrm{d}_{43}\right.$, in $\mu \mathrm{m})$ of oil-in-water emulsions $\left(10 \% w / \mathrm{w}\right.$ Miglyol oil, $5.0 \times 10^{-3}$ mol L ${ }^{-1}$ surfactant, $\mathrm{pH}$ 7) stabilized by glycyrrhizin and its corresponding aglycone $18 \beta$ glycyrrhetinic acid produced under standardized high-pressure homogenization conditions (10,000 psi, 4 cycles) during storage at different temperatures

\begin{tabular}{|c|c|c|c|c|c|c|}
\hline \multirow{2}{*}{$\begin{array}{l}\text { Time } \\
\text { (d) }\end{array}$} & \multicolumn{3}{|l|}{ Glycyrrhizin } & \multicolumn{3}{|c|}{ Glycyrrhetinic acid } \\
\hline & $5^{\circ} \mathrm{C}$ & $25^{\circ} \mathrm{C}$ & $55^{\circ} \mathrm{C}$ & $5^{\circ} \mathrm{C}$ & $25^{\circ} \mathrm{C}$ & $55^{\circ} \mathrm{C}$ \\
\hline 1 & $0.273 \pm 0.005$ & $0.425 \pm 0.076$ & $0.287 \pm 0.011$ & $0.310 \pm 0.010$ & $0.353 \pm 0.045$ & $0.306 \pm 0.008$ \\
\hline 7 & $0.290 \pm 0.006$ & $0.305 \pm 0.001$ & $0.273 \pm 0.014$ & $0.302 \pm 0.007$ & $0.277 \pm 0.003$ & Unstable $^{\mathrm{a}}$ \\
\hline 14 & $0.268 \pm 0.003$ & Unstable $^{\mathrm{a}}$ & Unstable $^{\mathrm{a}}$ & $0.294 \pm 0.003$ & $0.366 \pm 0.102$ & Unstable $^{\mathrm{a}}$ \\
\hline 21 & $0.290 \pm 0.012$ & Unstable $^{\mathrm{a}}$ & Unstable $^{\mathrm{a}}$ & $0.322 \pm 0.001$ & $0.318 \pm 0.012$ & Unstable $^{\mathrm{a}}$ \\
\hline 28 & $0.319 \pm 0.003$ & Unstable $^{\mathrm{a}}$ & Unstable $^{a}$ & $0.292 \pm 0.005$ & $0.302 \pm 0.001$ & Unstable $^{\mathrm{a}}$ \\
\hline 35 & $0.318 \pm 0.018$ & Unstable $^{\mathrm{a}}$ & Unstable $^{\mathrm{a}}$ & $0.309 \pm 0.008$ & Unstable $^{\mathrm{a}}$ & Unstable $^{\mathrm{a}}$ \\
\hline
\end{tabular}

${ }^{\mathrm{a}}$ Phase separation occurred. Particle size measurements provided irreproducible results 
and techno-functional properties still remains to be established by further molecular experiments, our results indicate especially glycyrrhizin as an effective naturally-derived surfactant for a variety of emulsion-based products in the food, cosmetic, and pharmaceutical industry. Its successful application will also depend on a range of factors including the taste profile, reliability of supply, and cost.

Acknowledgements Open Access funding provided by Projekt DEAL. The authors thank Johannes Dreher, Jonas Hilbig, Eva Herz, and Corina Reichert (all University of Hohenheim) for their continuous assistance at various measurement methods as well as during manuscript writing. In particular, T. R. thanks Hanna Bogner for countless essential and fruitful discussions.

Funding Information This IGF Project of the FEI is supported via AiF within the program for promoting the Industrial Collective Research (IGF) of the German Ministry of Economic Affairs and Energy (BMWi), based on a resolution of the German Parliament. Project AiF $18815 \mathrm{~N}$

\section{Compliance with Ethical Standards}

Conflict of Interest All authors declare that they have no conflict of interest. After experimental work, T.R. has taken up a position at a commercial manufacturer of carotenoids (DSM Nutritional Products, Kaiseraugst, Switzerland). After experimental work, K.B. has taken up a position at a commercial manufacturer of medicine and cosmetics (Wala Heilmittel, Bad Ball/Eckwälden, Germany). After experimental work, M.E. has taken up a position at a commercial manufacturer of pfarmaceuticals and medical device products (C.P.M. ContractPharma, Feldkirchen-Westerham, Germany).

Open Access This article is licensed under a Creative Commons Attribution 4.0 International License, which permits use, sharing, adaptation, distribution and reproduction in any medium or format, as long as you give appropriate credit to the original author(s) and the source, provide a link to the Creative Commons licence, and indicate if changes were made. The images or other third party material in this article are included in the article's Creative Commons licence, unless indicated otherwise in a credit line to the material. If material is not included in the article's Creative Commons licence and your intended use is not permitted by statutory regulation or exceeds the permitted use, you will need to obtain permission directly from the copyright holder. To view a copy of this licence, visit http://creativecommons.org/licenses/by/4.0/.

\section{References}

1. D.J. McClements, L. Bai, C. Chung, Annu. Rev. Food Sci. Technol. 8, 205-236 (2017)

2. E. Bouyer, G. Mekhloufi, V. Rosilio, J.-L. Grossiord, F. Agnely, Int. J. Pharm. 436(1), 359-378 (2012)
3. D. Oakenfull, Food Chem. 7(1), 19-40 (1981)

4. W. Oleszek, in Natural Food Antimicrobial Systems, ed. by A. Naidu. (CRC Press, Boca Raton, 2000), pp. 295-324

5. O. Güçlü-Ustündag, G. Mazza, Crit. Rev. Food Sci. Nutr. 47(3), 231-258 (2007)

6. W. Oleszek and A. Hamed, in Surfactants from Renewable Resources, edited by M. Kjellin and I. Johansson (John Wiley \& Sons, Ltd, 2010), pp. 239-249

7. Y. Yang, M.E. Leser, A.A. Sher, D.J. McClements, Food Hydrocolloid. 30(2), 589-596 (2013)

8. T. Ralla, H. Salminen, M. Edelmann, C. Dawid, T. Hofmann, J. Weiss, J. Agric. Food Chem. 65(20), 4153-4160 (2017)

9. S. G. Sparg, M. E. Light and J. van Staden, J. Ethnopharmacol. 94 (2-3), 219-243 (2004)

10. C. Schmid, C. Dawid, V. Peters, T. Hofmann, J. Nat. Prod. 81(8), 1734-1744 (2018)

11. T. Ralla, H. Salminen, K. Braun, et al., LWT 120, 108910 (2020)

12. K. Matsuoka, R. Miyajima, Y. Ishida, S. Karasawa, T. Yoshimura, Colloid. Surface., A 500, 112-117 (2016)

13. D.J. McClements, C.E. Gumus, Adv. Colloid Interfac. Sci. 234, 3 $26(2016)$

14. D.J. McClements, Food Emulsions: Principles, Practices, and Techniques (CRC Press, Boca Raton, 2015)

15. O. Frank, J. K. Kreissl, A. Daschner, T. Hofmann, J. Agric. Food Chem. 62 (12):2506-2515 (2014)

16. C.A. Schneider, W.S. Rasband, K.W. Eliceiri, Nat. Methods 9(7), 671 (2012)

17. K. Golemanov, S. Tcholakova, N. Denkov, E. Pelan, S.D. Stoyanov, Soft Matter 9(24), 5738 (2013)

18. S. Mitra, S.R. Dungan, J. Agr. Food Chem. 45(5), 1587-1595 (1997)

19. D.S. Wishart, Y.D. Feunang, A. Marcu, et al., Nucleic Acids Res 46(D1), D608-D617 (2018)

20. T. Ralla, E. Herz, H. Salminen, et al., Food Biophys. 12(4), 479490 (2017)

21. T. Ralla, H. Salminen, M. Edelmann, C. Dawid, T. Hofmann, J. Weiss, Food Biophys. 12(3), 269-278 (2017)

22. T. Ralla, H. Salminen, M. Edelmann, C. Dawid, T. Hofmann, J. Weiss, Food Hydrocolloid. 81, 253-262 (2018)

23. T. Ralla, H. Salminen, J. Tuosto, J. Weiss, Int. J. Food Sci. Tech. 53(6), 1381-1388 (2018)

24. T. Ralla, H. Salminen, T. Wolfangel, et al., Int. J. Food Sci. Tech. 54(3), 619-625 (2019)

25. S. Jood, B.M. Chauhan, A.C. Kapoor, J. Sci. Food Agric. 37(11), 1121-1124 (1986)

26. S. Ghosh, J.N. Coupland, Food Hydrocolloid. 22(1), 105-111 (2008)

27. S. Böttcher, S. Drusch, Adv. Colloid Interfac. Sci. 243, 105-113 (2017)

28. N. Pagureva, S. Tcholakova, K. Golemanov, N. Denkov, E. Pelan, S.D. Stoyanov, Colloid. Surface., A 491, 18-28 (2016)

29. K. Golemanov, S. Tcholakova, N. Denkov, E. Pelan, S.D. Stoyanov, Langmuir 28(33), 12071-12084 (2012)

Publisher's Note Springer Nature remains neutral with regard to jurisdictional claims in published maps and institutional affiliations. 